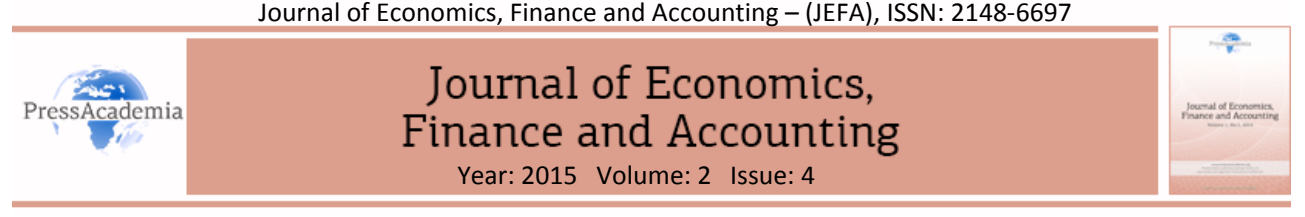

\title{
LEVERAGE PROCYCLICAL OF TURKISH DEPOSIT BANKS ${ }^{1}$
}

\section{DOI: 10.17261/Pressacademia.2015414367}

\section{Mustafa Terzioglu', Yusuf Demir ${ }^{2}$}

${ }^{1} A k d e n i z$ University. mterzioglu@akdeniz.edu.tr

${ }^{2}$ Süleyman Demirel University. yusufdemir@sdu.edu.tr

\section{Keywords}

Leverage, procyclicality, Turkish Banking Sector, deposit banks, financial crisis.

JEL Classification

G21, G28, G01

\section{ABSTRACT}

The studies after 2008 financial crisis emphasized that the concept of leverage procyclicality is among the major reasons of this crisis. BASEL II utilized during this crisis period has failed to foresee the risk. This procyclicality in financial expansion and contraction periods has wider impacts for developing economies such as Turkey. The current study has looked into the procyclicality of leverage ratios for deposit banks in Turkey. This research has focused on the association between change in total assets and leverage ratios for top ten deposit banks in Turkey by using the least square method. Data span is between December 2002 and December 2014, which has been assessed in quarterly periods. The study concluded that leverage ratios in Turkish banking industry is procyclical and leverage procyclicality can be implemented as a market control mechanism for Turkey.

\section{TÜRK MEVDUAT BANKALARININ KALDIRAÇ DÖNGÜSELLIĞi}

Anahtar Kelimeler

Kaldıraç, döngüsellik, Türk Bankacılık Sektörü, ticari bankacılık, finansal krizler.

JEL Sınıflandırması G21, G28, G01

\section{ÖZET}

Kaldıraç döngüselliği kavramı 2008 Mali krizinin sonrasında yapılan akademik çalışmalarda bu mali krizinin en önemli nedenleri arasında gösterilmektedir.Kriz döneminde kullanılan BASEL II de bu riski öngörebilmekte yetersiz kalmıştır. Özellikle, Türkiye gibi gelişmekte olan piyasaların finansal genişleme ve daralma dönemlerinde bu döngüselliğin yaratabileceği tahribat daha fazla olabilmektedir. Bu çalışmada Türk bankacılık sisteminde faaliyet gösteren mevduat bankalarına ait kaldıraç oranlarının döngüselliği incelenmiştir. Araştırmada Türkiye'deki ilk on mevduat bankasının aktif değişimleri ile kaldıraç oranlarının değişimi arasındaki bağıntı en küçük kareler yöntemi kullanılarak test edilmiştir. Veri aralığı Aralık 2002 ile Aralık 2014 arasında olup çeyrek dönemler itibariyle değerlendirilmiştir. Çalışmada Türk bankacılık sektörünün kaldıraç oranlarının döngüsel olduğu sonucuna ulaşılarak kaldıraç döngüselliğinin Türkiye için bir piyasa kontrol mekanizması olarak kullanılabileceği sonucuna ulaşılmıştır.

\footnotetext{
${ }^{1}$ Bu makale, 21-24 Ekim 2015 tarihleri arasında yapılan 19.Finans Sempozyumu'nda bildiri olarak sunulmuştur.
} 


\section{GíRiş}

Tüm iktisadi kuruluşların temel çalışma prensiplerinden bir tanesi de elde ettikleri kaynakları doğru bir şekilde varlık haline dönüştürmektir. Bu dönüşüm sürecinin kaynak tarafı, özkaynak ve yabancı kaynak olmak üzere iki temel yapıdan oluşmaktadır. iktisadi kurumların varlıklarının özkaynaklarına oranlandığında, bu orana kaldıraç oranı denmektedir. Bu kurumlar özellikle finansal genişleme dönemlerinde varlıkları değerlendiğinde düşen kaldıraç oranlarını yükseltmek için daha fazla kaynak bulma yoluna gitmektedirler. Bu durum finans literatüründe "kaldıracın döngüselliği" olarak adlandırılmaktadır. Bu döngünün tam tersi durumu ise finans "kaldıracın döngüsel karşıtlı̆̆ı" olarak adlandırılmaktadır.

Bu kaldıraç mekanizmasının bankalar için önemi nereden kaynaklanmaktadır? Bunu Kalemli-Ozcan ve diğ.'nin (2011), "The Adrian-Shin Model" diye adlandırdığı Adrian ve Shin(2008, 2010)'in çalışmalarında ortaya koymuş oldukları döngüyle açıklamak mümkündür. Bu döngü Şekil 1'de görülmektedir.

Şekil 1: Adrian-Shin Kaldıraç Döngüselliği
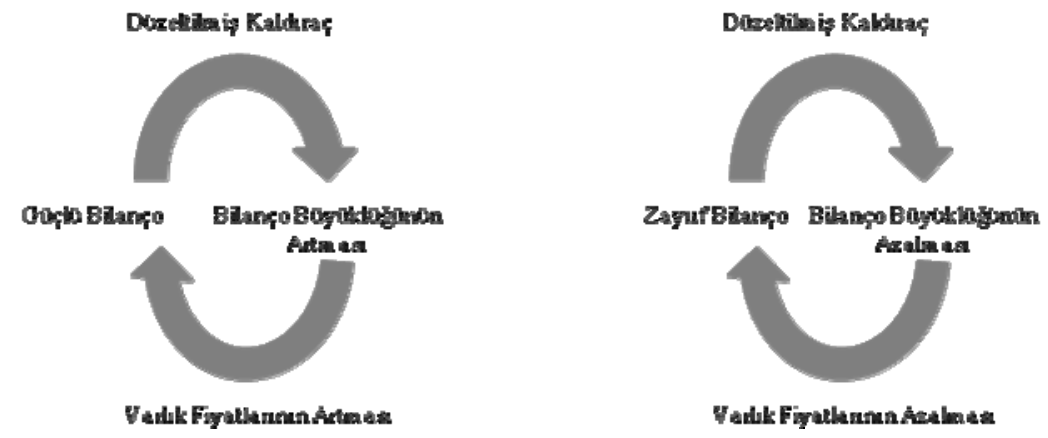

Şekil 1'de görüldüğü gibi modelin ilk döngüsünde bankalar varlık değerlerinin artması sonucu, düşen kaldıraç oranlarından dolayı koydukları kaldıraç hedeflerine ulaşabilmek için daha fazla kaynak bulma yoluna gitmektedirler. Bu durum bankaların bilanço büyüklüklerinin artmasına neden olmaktadır. Bu da kaldıraç oranının yukarıda da ifade edildiği gibi döngüsel olduğunu ispat etmektedir. Diğer bir ifadeyle, bankalar büyüme gösterdiğinde kaldıraç oranı da artmaktadır. Modelin diğer döngüsünde ise varlık değerlerinin azalması sonucu bankalar yükselen kaldıraç oranlarını düşürme eğilimine girmekte ve bu da bilanço büyüklüklerini düşürmektedir. Bu duruma ise döngüselliğin karşıtlı̆̆ı denmektedir. (Adrian ve Shin, 2010: 420-424).

Bankaların artan varlık değerleri için kaldıraç oranlarını arttırmak istemesi ne anlama gelmektedir? Bankaların kaldıraç oranlarını arttırmak istemesinin iki önemli nedeni vardır. Bunlardan birincisi, bankaların özkaynak karlılığı (Return of Equity-ROE) ve aktif kârlılığı (ROA) değerlerini, artan varlık değerlerindeki artışa bağlı olarak artırma istekleridir. İkincisi de koymuş oldukları kaldıraç hedeflerini (bu BASEL III gibi yasal zorunluluklardan kaynaklanmaktadır) tutturmak istemeleridir. Ancak, bankalar hem bu yüksek kâr hem de 
düşen kaldıraç oranlarını yüksek seviyede tutma isteğiyle, finansal sistemlerde kontrol edilemeyen bir kredi genişlemesi yaratabilmekte ve ekonomik krizin oluşumuna da katkıda bulunabilmektedirler. Bu durumun iyi tarafı da bulunmaktadır. Ülkelerdeki finansal sistemi düzenleyen kuruluşlar bankaların kaldıraç oranlarını gözetim altında tutarak ya da yeni kurallar koyarak ekonomilerinin istikrarını koruyabilecek bir enstrüman olarak kaldıraç döngüselliğini kullanabileceklerdir. Aynı şekilde, bankalar da kendi yönetim yapılarında kaldıraç yönetimi kullanarak olası riskleri bertaraf edebilirler. Örneğin, piyasa düzenleyici kurumlar kredi ve varlık artışlarını kısıtlamaya yönelik politikalar oluşturarak bu döngüselliği yavaşlatabilirler ya da en azından zayıflatarak daha yumuşak geçişi tesis edebilirler.

Kaldıraç döngüselliğinin kriz önleyici bir mekanizma olarak kullanılması gerekliliği ilk önce $A B D^{\prime}$ de başlamış ve tüm dünyaya yayılmıştır. Bu da bankacılık sisteminin arz yönlü bir büyüme stratejisi benimsemesine neden olmuştur.

Bilindiği gibi 2002-2007 yılları arasında büyük bir ivme kazanan ve finansal bir balon haline gelen, daha sonra 2009 yılında bu balonun patlamasıyla tetiklenen mali krizin ana nedenlerinden birisinin de kaldıraç döngüselliği olduğunu bir çok akademisyen kabul etmiştir. Bahsedilen krizde, finansal genişleme esnasında varlık değerleri artmış ve bunun sonucu olarak kaldıraç değerlerinin banka hedeflerinin altına inmesiyle bu döngü başlamıştır. Varlık fiyatları yukarı doğru gittikçe, bu kurumlar kaldıraç hedefleri doğrultusunda daha fazla varlık satın almışlar (hatta gereğinden fazla) ve bunun finansmanı için de yabancı kaynaklarını arttırmışlardır. Bu yüksek geri kaldıraç beslemeleri sırasında yaşanan varlık değerlerindeki şok değer düşüşleri bu mekanizmayı ters çalıştırmıştır. Bunun sonucunda bankaların bilançolarında ılımlı para politikalarının da devreye girmesiyle ciddi anlamda küçülmeler ve hatta iflaslar yaşanmıştır (Baglioni ve diğ., 2013: 1252). Oysa bu kaldıraç döngüselliği yönetimi, hem bankalarda hem de finansal sistemi düzenleyici kurumlarda var olsaydı kriz daha derinleşmeden önlenmesi söz konusu olabilirdi.

Özellikle, bu mali krizden sonra döngüselliği yeterince dikkate almamasıyla eleştirilen BASEL II'ye bu yöndeki eksikliğini kapatmak amacıyla, ülke şartlarına ve tercihlerine bağlı olarak \%0 ilâ \%2,5 arasında değişen döngüsel sermaye tamponu uygulaması getirilmiştir. Basel III'te ise kaldıraç oranın 2017'de \%3 olarak gerçekleştirilmesi hükmü bulunmaktadır (BASEL Komitesi, 2010: 2).

Bu çalışmada 2003 ve 2014 yılları arasında Türkiye'deki bankacılık sisteminin kaldıraç oranlarının döngüselliği analizi yapılmıştır. Çalışmada öncelikle kaldıraç oranlarının döngüselliğinin ne olduğu ve literatürdeki benzer çalışmalara yer verilmiş. İkinci kısımda Türkiye'deki bankalar üzerine bir analiz uygulanmıştır. Bunun için varlık büyüklükleri itibariyle ilk on büyük mevduat bankası tercih edilmiştir. Kaldıraç oranları olarak literatürde sıklıkla kullanılan aktif/özkaynak ve borç/özkaynak oranları kullanılmıştır. Bu oranların bankaların aktif büyüme ile bağıntısı araştırılarak Türk banklarının kaldıraç oranlarının döngüselliği diğer bir ifadeyle ekonominin genişlediği dönemlerde kaldıraç oranlarının artıp artmadığı test edilmiştir. Bunun için istatistiki olarak sıklıkla kullanılan ve güvenilir sonuçlar veren En Küçük Kareler Yöntemi uygulanmıştır. 


\section{LITERATÜR ARAŞTIRMASI}

Kaldıraç döngüselliğine yönelik çalışmalar özellikle yaşanan global bankacılık krizinden sonra artmış olsa da akademik olarak fazlaca irdelenmiş bir konu değildir.

Kaldıraç oranlarını döngüselliğe yönelik en önemli çalışmalar Adrian ve Shin'in (2008 ve 2010) yapmış olduğu çalışmalardır. Bu çalışmalarında 1997 ve 2008 yılları arasında Amerika Birleşik Devletleri'ndeki beş büyük yatırım bankasının (Bear Stearns, Goldman Sachs, Lehman Brothers, Merrill Lynch ve Morgan Stanley) kaldıraç politikalarını analiz etmişler ve bu bankaların kaldıraç oranlarının döngüsel olduğu sonucuna ulaşmışlardır. Bu bankaların kendi varlık değerlerinin arttığı durumlarda buna cevap olarak bilanço boyutlarını arttırdıklarını ve daha fazla yabancı kaynak edinerek daha fazla borç verir bir pozisyona döndüklerini tespit etmişlerdir. Aynı zamanda bu çalışmalarında, adı geçen bankaların finansal gelişme döneminde düşük riskten ötürü kaldıraç oranlarını yüksek tuttuklarını, riske maruz değer (VaR) modeliyle açıklamışlardır.

Damar ve diğ. (2010) 1994-2009 yılları arasında Kanada'da faaliyet gösteren 242 yerel banka üzerinde yapmış oldukları çalışmada, kaldıraç olarak Varlıklar+Bilanço Dışı Varlıklar/ Yasal Özkaynaklar oranını kullanmışlardır. Çalışmada bu oran ile bankaların aktif büyüklüğü arasında pozitif bir bağıntı (döngüsellik) var olduğunu tespit etmişlerdir.

Gropp ve Heider (2010) Amerika Birleşik Devletleri ve 15 Avrupa Birliği Ülkesinde faaliyet gösteren ticari bankalar ve diğer finans kuruluşları üzerinde 1994- 2004 yıllarını kapsayan çalışmalarında sermaye yapısını incelerken, bankaların kaldıraç davranışlarının zaman içinde değişmeyen ve kendine özgü bir yapıda olduklarını tespit etmişlerdir.

Kalemli-Ozcan ve diğ. (2011) 2000-2009 dönemini kapsayan başta Amerika Birleşik Devletleri olmak üzere 23 ülke üzerinde yapmış oldukları çalışmalarında bankaların, banka dışı firmaların ve ülkelerin kaldıraç oranlarını analize tabi tutmuşlardır. Bu çalışmada değişik sonuçlara ulaşılmıştır. Çalışmada, Amerika Birleşik Devletleri'ndeki yatırım bankaları ve büyük varlık değerine sahip ticari bankaların kaldıracının döngüsel olduğu ancak Avrupa kıtasında bu döngüselliğin daha küçük olduğu tespit edilmiştir. Bunun yanında araştırmada bir başka önemli tespit ise özellikle Türkiye gibi büyüyen pazarlarda yatırımcıyı korumak, bankaları disiplin altına almak ve ekonomik krizlerden en az şekilde etkilenmesi amacıyla getirilen düzenleyici kurallar nedeniyle kaldıraç döngüselliğinin oldukça sınırlı olduğu sonucuna ulaşılmış olmasıdır.

Danielsson ve diğ. (2012) yapmış oldukları model çalışmasında Fisher Black kaldıraç efekti üzerinden hareketle kriz dönemlerinde dengeli bir kaldıraç yönetiminin nasıl yapılabileceğini risk primi, asimetrik oynaklık ve opsiyon fiyatlama üzerinden kurmuş oldukları bir model ile açıklamışlardır.

Baglioni ve diğ. (2013) 2000-2009 yıllarını kapsayan 18 Avrupa ülkesindeki yatırım ve ticari bankalar üzerinde kaldıraç oranı döngüselliğinin etkilerine yönelik yapmış oldukları çalışmada bu bankalarının kaldıraç oranı döngüselliğinin yerleşmiş bir davranış şekli olduğu sonucuna ulaşmışlardır. Buradan da bu döngüselliğin finansal genişleme dönemleri kadar 
kriz dönemlerinde de arz yönlü bir finansal hızlandırıcı mekanizma olduğu sonucuna ulaşmışlardır.

Giordana ve Schumacher (2013) Lüksemburg bankacılık sektöründeki 2003-2010 yılları arasındaki döngüselliği test eden çalışmalarında, bu bankaların genel olarak kaldıraçlarının döngüsel olduğu sonucuna ulaşmışlardır. Çalışmada Lüksemburg'da faaliyet gösteren bankaların holding bankaları olmaları sebebiyle mali kriz öncesi bu holdinglerin hissedarlarının yüksek kâr payından yararlanmak için kaldıracı bir risk olarak göremedikleri ancak kriz döneminde ana ve yavru şirketlerin yaşadığı likidite sıkıntısı nedeniyle bu bankaların daha da sıkıntıya düştükleri tespitinde bulunmuşlardır.

Petersen ve diğ. (2013) 2000-2011 yılları arasında ve aralarında Türk bankacılık sektöründe de faaliyet gösteren toplam 305 banka üzerinde yapmış oldukları çalışmada bankalar öncelikle Sınıf 1 ve Sınıf 2 olarak ayrılmıştır. Sınıf 1 bankalar TIER I sermayesi ve riske gore ağırlıklandırılmamış varlıklar toplamı 4 Milyar\$ ile 100 Milyar\$ arasındaki uluslararası faaaliyet gösteren bankalar, Sınıf 2 bankalar ise bu kıstas dışında kalan bankalar olarak belirlenmiştir. Yüksek oranlı hesaplanan BASEL III kriteri kaldıraç standardının hem Sınıf 1 hem de Sınıf 2 deki bankaların stresini tam olarak ölçemediği sonucuna ulaşmışlardır. Bu sonuçtan hareketle araştırmacılar tek tip BASEL III kaldıraç standardı yerine daha kapsayıcı bir düzenlemenin gerekliliğini vurgulamışlardır.

Brumitt ve diğ. (2014) yapmış oldukları modellemede bankaların negatif şok yaşatabilecek sistematik riskin bu kurumların nakit ve kaldıraç döngüselliği olduğunu ortaya çıkarmışlardır. 2008 yılında yaşanan mali krizde FED (ABD Merkez Bankası) ve ABD’nin Hazinesi'nin varlık fiyatları ve kaldıraç döngüselliğine yönelik ortak politikalar oluştursalar idi bankacılık sektörünün daha dengeli çalışabileceğini bu model ile ispatlamışlardır. Bunun yanında araştırmacılar kurmuş oldukları model ile aşırı iyimserliğin ters etki göstererek piyasalar için felaket ile sonuçlandığı önermesinde bulunmuşlardır.

Athanasoglou ve diğ. (2014) hazırlamış oldukları liteartür incelenmesine yönelik çalışmada son küresel mali krizin kaldıraç döngüselliğinin kontrol gerekliliğinin ne kadar önemli olduğu vurgulamışlardır. Özellikle BASEL II'ye yönelik yapılan teorik çalışmaların kaldıracın döngüselliği tehdidini fark edemediği çalışmada gösterilmiştir. Çalışmada ayrıca, Muhasebe standartlarındaki değişiklikler ve BASEL III uygulamaları ile döngüselliğin negatif etkilerini gidermede önemli bir rol oynayacağı da ifade edilmiştir.

Türkiye'de kaldıraç oranlarının döngüselliğine yönelik çalışmalar oldukça sınırlıdır.

Çalışkan (2011), 1994-2009 yılları arasında Türk Bankaları üzerine yapmış olduğu analizde 2001 krizinden sonra Türk Bankacılık sisteminin kaldıraç oranının ABD’ndeki bankacılık sistemine göre oldukça düşük kaldığını tespit etmiş ve Türk Bankalarının kaldıraç döngüselliği davranışı sergilediğini ifade etmiştir. Ancak Çalışkan'a göre 2001 sonrası getirilen sıkı bankacılık düzenlemeleri ve denetlemelerinden dolayı kaldıraç büyüme hızı anlamlı bir şekilde yavaşlamıştır. Bu durum aynı dönemlerde ABD’nde finansal serbestleşmenin tam tersi bir eğilim sergilemiştir. 
Binici ve Köksal (2012), Türk Bankacılık sisteminde kaldıraç ile aktif büyüme arasındaki ilişkileri 2002-2011 dönemi için analiz etmişlerdir. Analiz sonuçları göre Türk Bankacılık sektörü için kaldıraç oranın döngüsel olduğu ve bunun finansal hızlandırıcı bir mekanizma olarak çalıştığı görüşüne ulaşmışlardır.

\section{VERI VE METODOLOJi}

Çalışmada 2014 yılı son çeyreği itibariyle aktif büyüklüğüne göre sıralan Türkiye'deki ilk 10 ticari banka analize tabi tutulmaktadır. Örneklem olarak bu 10 bankanın seçilmesinin nedeni Türk bankacılık sistemindeki toplam aktif büyüklüğünün \%85,38 ${ }^{2}$ 'ini $(2014 / 4$ itibariyle) temsil etmesinden kaynaklanmaktadır. Böylece bu örneklem ile Türk bankacılık sektörünün kaldıraç döngüselliğinin ortaya konulacağı düşünülmektedir. Bu bankaların yedisi özel sektör bankası olup, üç tanesi de kamu bankasıdır. Çalışmada En Küçük Kareler yöntemi uygulanmaktadır. Analiz işlemleri genel sektör, özel sektör ve kamu sektör olarak üç farklı grupta da yapılmaktadır. Bu bankalar alfabetik olarak Tablo 1'deki gibidir.

\section{Tablo 1: Türkiye'deki Aktif Büyüklüğüne Göre illk On Banka}

\begin{tabular}{|l|l|c|c|c|}
\hline Sıra & Banka Adı & Tür & Aktif Büyüklük $^{\mathbf{3}} \mathbf{( 1 . 0 0 0}$ TL) & Çalışmadaki Kodu $^{\text {AKBANK }}$ \\
\hline 1 & Akbank T.A.Ş. & Özel & 205.450 .620 & DENIZ \\
\hline 2 & Denizbank A.Ş. & Özel & 69.474 .016 & FINANS \\
\hline 3 & Finansbank A.Ş. & Özel & 75.206 .354 & TEB \\
\hline 4 & Türkiye Ekonomi Bankası A.Ş. & Özel & 62.991 .889 & ZIRAAT \\
\hline 5 & T.C. Ziraat Bankası A.Ş. & Kamu & 247.600 .311 & GARANTI \\
\hline 6 & Türkiye Garanti Bankası A.Ş. & Özel & 218.918 .504 & HALK \\
\hline 7 & Türkiye Halk Bankası A.Ş. & Kamu & 155.423 .019 & VAKIF \\
\hline 8 & Türkiye İş Bankası A.Ş. & Özel & 237.771 .975 & YAPI \\
\hline 9 & Türkiye Vakıflar Bankası T.A.O & Kamu & 158.217 .726 & 181.201 .285 \\
\hline 10 & Yapı ve Kredi Bankası A.Ş. & Özel &
\end{tabular}

Kaynak: Türkiye Bankalar Birliği, http://www.tbb.org.tr/tr/banka-ve-sektor-bilgileri/veri-sorgulamasistemi/60, Mart 2015.

Hem bankacılık sektöründe hem de literatürde birçok kaldıraç oranı tanımlamakla birlikte çalışmada bu oranlardan en yaygın olarak kullanılan aktif/özkaynak ve borç/özkaynak oranları kullanılacaktır. Bu oranların dönemler itibariyle artışı bankaların kaldıracının arttığını tersi durum ise kaldıracının azaldığı anlamına gelmektedir. Çalışmada, örneklemdeki bankaların aktif değişimi ve kaldıraç değişimi arasındaki etkileşim ele alınarak döngüsellik test edilmiştir. Aktif ve kaldıraç oranlarındaki pozitif etkileşim döngüselliğin meydana geldiğini, negatif değişim ise döngüselliğin bulunmadığını göstermektedir.

Çalışmada kullanılan veriler Türkiye Bankalar Birliği'nin internet sitesinde yayımlanan Veri Sorgulama Sistemi'nden elde edilmiştir. Veri aralığı olarak bu verilerin yayımlandığı tarih

\footnotetext{
${ }^{2}$ Türkiye Bankalar Birliği'ne göre 2014 son çeyreğindeki tüm bankaların aktif büyüklüğü 1.888.308.478.000 TL olup, örneklem için seçilen ilk on ticari bankanın aktif büyüklüğü 1.612.255.699.000 TL'dir.

${ }^{3}$ 2014/4 Çeyrek rakamlarına göre
} 
başlangıcı olan 2002/4 çeyreği ile 2014/4 çeyreği aralığını kapsamaktadır. Veriler En Küçük Kareler Yöntemi ile çeyreklik dönemler itibariyle analize tabi tutulmaktadır.

\section{ARAŞTIRMANIN BULGULARI}

$\mathrm{Bu}$ bölümde öncelikle ilgili zaman aralığında örneklem olarak seçilen bankaların aktif/özkaynak ve borç/özkaynak kaldıraç oranlarının grafikleri verilecektir.

\section{Şekil 2: Kaldıraç Oranları Grafiği}
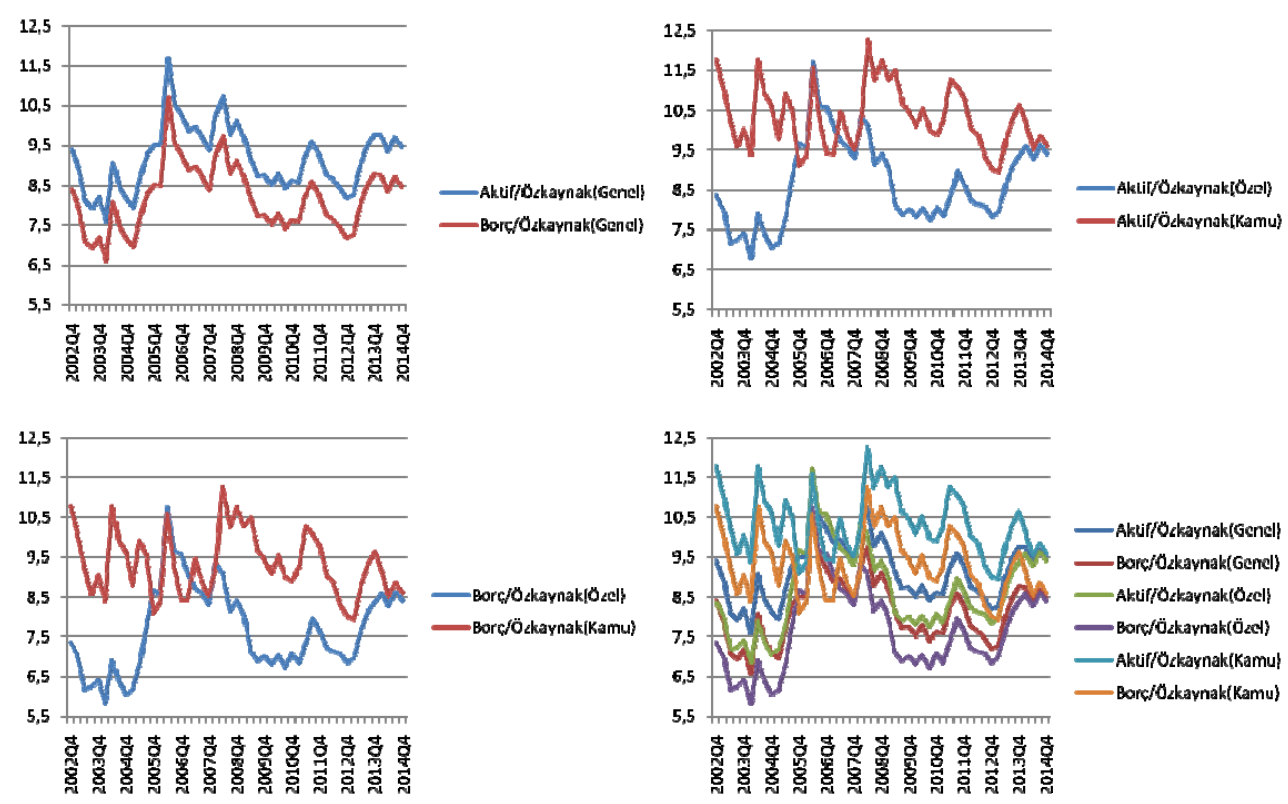

Şekil 2'de 2008'in ortalarında başlayan finansal krizin bankaların kaldıraç oranlarında bir düşüşe neden olduğu açıkça görülmektedir. Bu durum esasen kaldıraç oranlarının genel itibariyle döngüsel olduğunu ortaya koymaktadır. Finansal daralmanın yaşandığı bu dönemde bankaların kaldıraç oranlarının düştüğünün açıkça görülmesi bu döngü hakkında küçükte olsa bir bilgi vermektedir. Kriz sonrası kaldıraç oranlarındaki artış ise yine döngüselliğin yaşandığını göstermektedir. Şekil 2'den çıkarılabilecek diğer bir sonuç ise kamu bankalarının kaldıraç oranlarının belli bir esneklikte devam etmesine rağmen özel banklarının daha dalgalı bir yapı göstermeleridir. Bu durum finansal krizin özel bankacılık sektörünü, kaldıraç oranları bazında daha fazla etkilediğinin bir göstergesidir.

Ancak kaldıraç oranlarının döngüselliğini tam olarak ifade edebilmek için bankaların bu oranları ile aktif büyüklükleri arasındaki ilişki ile birlikte ortaya konulması gerekmektedir. Şekil 3'de bu etkileşimin grafikleri görülmektedir. 
Şekil 3: Aktif Değişim ile Kaldıraç Oranlarının Değişimi Arasındaki Etkileşim
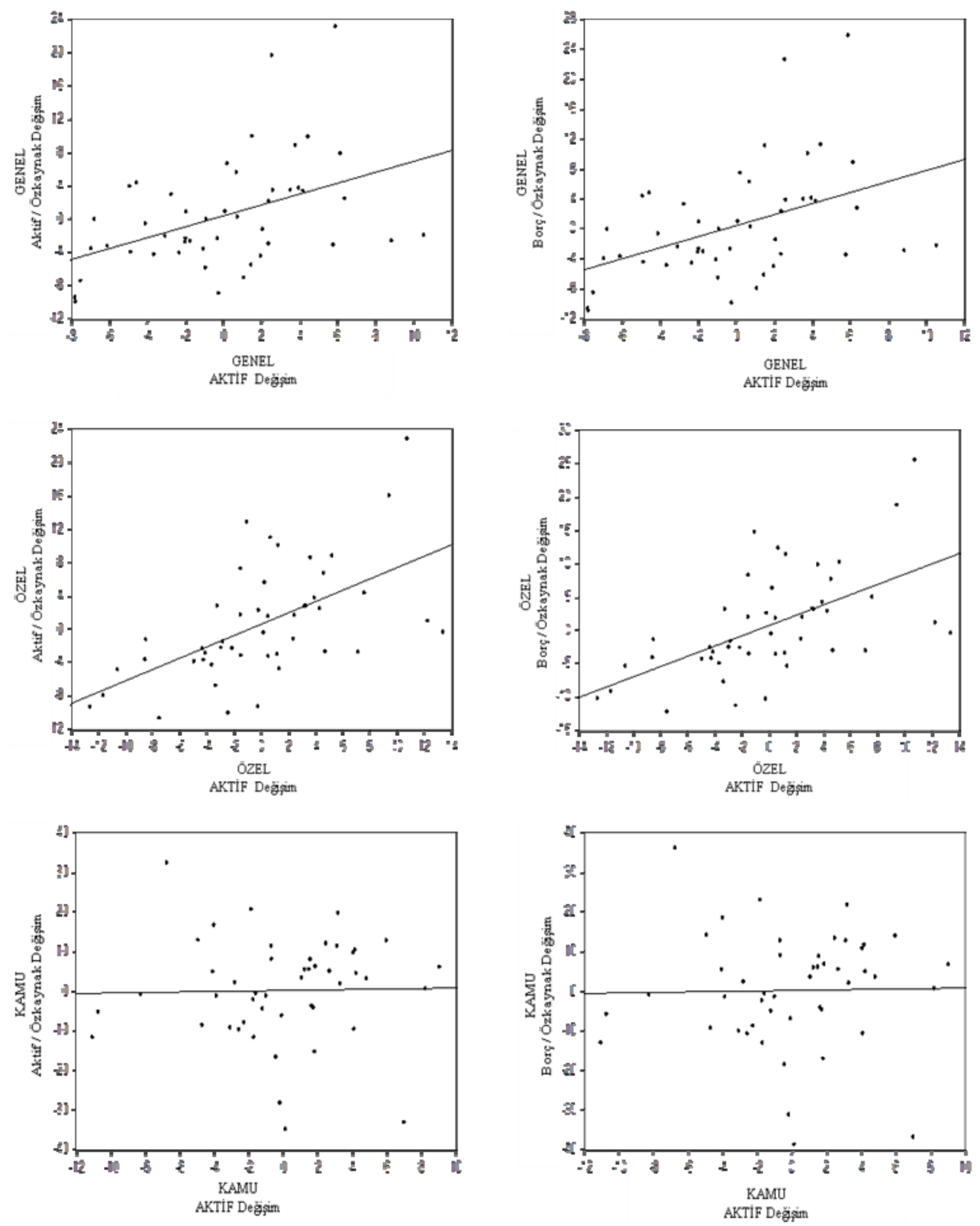

Şekil 3’de görüldüğü gibi genel olarak bankaların bilânçolarındaki aktif değişim ile kaldıraç oranları arasında pozitif ve güçlü bir etkileşim vardır. Bu durum bu oranların döngüsel olduğunu göstermektedir. Ancak kamu bankalarının özel bankalara kıyasla çok daha sınırlı etkileşimde olduğu grafiklerde açıkça görülmektedir. Bunun nedeni kamu bankalarının 
kaynak yaratmasında özel bankalara göre (sendikasyon kredisi, tahvil ihracı vb.) daha sınırlı bir pozisyonu tercih etmesinin yattığı söylenebilir.

Analizin bu aşamasında bankaların aktif değişim ile kaldıraç oranlarının dönemsel değişim kullanılarak bu iki değişken arasındaki bağıntı ortaya konulmaktadır. Bu analiz için En Küçük Kareler Yöntemi uygulanmaktadır. Her bir banka üzerinde yapılan bu analiz ayrıca bankaların bulundukları grup (genel, özel, kamu) durumuna göre de yapılmaktadır. Tüm değişkenler $M^{C}$ Kinnon (1996) tarafından geliştirilen Augmented Dickey Fuller (ADF) Birim Kök Testi tarafından \%1 anlamlılık düzeyinde test edilerek, durağan olmayan değişkenler durağanlaştırılmıştır. Tablo 3'de En Küçük Kareler yöntemi sonuçları gösterilmektedir. Sonuçlar \%1, \%5, \%10 anlamlılık düzeyinde test edilmiştir.

\section{Tablo 3: En Küçük Kareler Yöntemi Sonuçları}

\begin{tabular}{|c|c|c|c|c|c|}
\hline \multicolumn{6}{|c|}{ Bağımlı Değişken: Aktif/Özkaynak Değişimi } \\
\hline \multirow{14}{*}{ 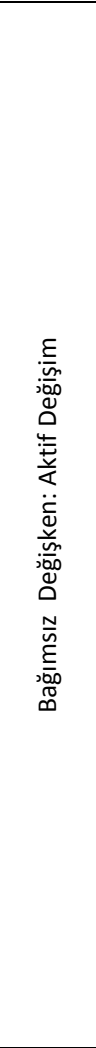 } & Banka & $\begin{array}{l}\text { Katsayı } \\
\text { (Prob) }\end{array}$ & $\begin{array}{c}\text { Düzeltilmiş R } \\
\text { (Prob F Statistic) }\end{array}$ & $\begin{array}{c}\text { LM Test } \\
\text { Obs }^{*} \mathrm{R} \text { squared } \\
\text { (Prob.Chi } \\
\text { Square) }\end{array}$ & $\begin{array}{l}\text { W. Heteroskedasticity }{ }^{\perp} \\
\text { Obs }{ }^{\perp} \text { squared } \\
\text { (Prob.Chi Square) }\end{array}$ \\
\hline & AKBANK $^{*}$ & $\begin{array}{c}0,455778 \\
(0,0030)\end{array}$ & $\begin{array}{c}0,179003 \\
(0,003047)\end{array}$ & $\begin{array}{l}17,53267 \\
(0,02501)\end{array}$ & $\begin{array}{c}1,664036 \\
(0,1971)\end{array}$ \\
\hline & DENIZ & $\begin{array}{c}0,531402 \\
(0,0000)\end{array}$ & $\begin{array}{c}0,498697 \\
(0,000000)\end{array}$ & $\begin{array}{c}5,346288 \\
(0,72)\end{array}$ & $\begin{array}{c}0,037116 \\
(0,8472)\end{array}$ \\
\hline & FINANS $^{*}$ & $\begin{array}{c}0,612100 \\
(0,0000) \\
\end{array}$ & $\begin{array}{c}0,470296 \\
(0,000000) \\
\end{array}$ & $\begin{array}{c}14,88721 \\
(0,0614) \\
\end{array}$ & $\begin{array}{c}1,588977 \\
(0,2075) \\
\end{array}$ \\
\hline & $\mathrm{TEB}^{* * *}$ & $\begin{array}{r}0,044241 \\
(0,7364)\end{array}$ & $\begin{array}{c}-0,019198 \\
(0,736392)\end{array}$ & $\begin{array}{c}11,88740 \\
(0,1563)\end{array}$ & $\begin{array}{c}31,59434 \\
(0,0000)\end{array}$ \\
\hline & ZIRAAT $^{* *}$ & $\begin{array}{c}0,051584 \\
(0,7224) \\
\end{array}$ & $\begin{array}{c}-0,018909 \\
(0,7223882)\end{array}$ & $\begin{array}{c}11,62210 \\
(0,1689)\end{array}$ & $\begin{array}{r}32,48159 \\
(0,0000)\end{array}$ \\
\hline & GARANTI $^{*}$ & $\begin{array}{c}0,655028 \\
(0,0000) \\
\end{array}$ & $\begin{array}{c}0,368114 \\
(0,000004) \\
\end{array}$ & $\begin{array}{c}8,302849 \\
(0,4045) \\
\end{array}$ & $\begin{array}{c}7,162145 \\
(0,074) \\
\end{array}$ \\
\hline & HALK $^{* * *}$ & $\begin{array}{c}0,616139 \\
(0,0304)\end{array}$ & $\begin{array}{c}0,07986 \\
(0,03363)\end{array}$ & $\begin{array}{c}92,51883 \\
0,0001\end{array}$ & $\begin{array}{c}0,655137 \\
(0,4183)\end{array}$ \\
\hline & ISBANK $^{*}$ & $\begin{array}{c}0,981781 \\
(0,0008) \\
\end{array}$ & $\begin{array}{c}0,202228 \\
(0,000791) \\
\end{array}$ & $\begin{array}{c}3,841254 \\
(0,8712) \\
\end{array}$ & $\begin{array}{c}1,841598 \\
(0,0308)\end{array}$ \\
\hline & VAKIF $^{* *}$ & $\begin{array}{c}0,362057 \\
(0,0234)\end{array}$ & $\begin{array}{c}0,089251 \\
(0,023392)\end{array}$ & $\begin{array}{c}8,149532 \\
(0,4190)\end{array}$ & $\begin{array}{c}0,1126093 \\
(0,7225)\end{array}$ \\
\hline & YAPI $^{* * *}$ & $\begin{array}{r}0,056185 \\
(0,7012)\end{array}$ & $\begin{array}{l}-0,018846 \\
(0,701210)\end{array}$ & $\begin{array}{c}10,39789 \\
(0,2382)\end{array}$ & $\begin{array}{c}0,021159 \\
(0,8843)\end{array}$ \\
\hline & "GENEL ${ }^{*}$ & $\begin{array}{c}0,653082 \\
(0,0022) \\
\end{array}$ & $\begin{array}{c}0,171932 \\
(0,002191) \\
\end{array}$ & $\begin{array}{c}1,882719 \\
(0,3901) \\
\end{array}$ & $\begin{array}{c}0,729492 \\
(0,3930) \\
\end{array}$ \\
\hline & ÖZEL $^{*}$ & $\begin{array}{c}0,679265 \\
(0,0000) \\
\end{array}$ & $\begin{array}{c}0,313375 \\
(0,000002)\end{array}$ & $\begin{array}{c}6,933893 \\
(0,5438) \\
\end{array}$ & $\begin{array}{c}2,442390 \\
(0,1181) \\
\end{array}$ \\
\hline & $\mathrm{KAMU}^{* * *}$ & $\begin{array}{c}0,061644 \\
(0,9019) \\
\end{array}$ & $\begin{array}{c}-0,021788 \\
(0,890579) \\
\end{array}$ & $\begin{array}{c}33,22858 \\
(0,0001) \\
\end{array}$ & $\begin{array}{r}0,030581 \\
(0,8612) \\
\end{array}$ \\
\hline & & Bağ & eğişken: Borç/Özk & ak Değişimi & \\
\hline 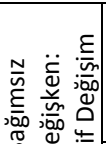 & Banka & $\begin{array}{l}\text { Katsayı } \\
\text { (Prob) }\end{array}$ & $\begin{array}{c}\text { Düzeltilmiş R } \\
\text { (Prob F Statistic) }\end{array}$ & $\begin{array}{c}\text { LM Test } \\
\text { Obs }^{*} \mathrm{R} \text { squared } \\
\text { (Prob.Chi } \\
\text { Square) }\end{array}$ & $\begin{array}{c}\text { W. Heteroskedasticity }{ }^{\perp} \\
\text { Obs }{ }^{*} \text { squared } \\
\text { (Prob.Chi Square) }\end{array}$ \\
\hline$\infty 0 \frac{\bar{\alpha}}{\dot{\alpha}}$ & AKBANK $^{*}$ & $\begin{array}{c}0,540071 \\
(0,0028) \\
\end{array}$ & $\begin{array}{c}0,163681 \\
(0002798) \\
\end{array}$ & $\begin{array}{c}17,81195 \\
(0,0227) \\
\end{array}$ & $\begin{array}{c}1,719493 \\
(0,1898) \\
\end{array}$ \\
\hline
\end{tabular}




\begin{tabular}{|c|c|c|c|c|}
\hline DENIZ & $\begin{array}{c}0,600950 \\
(0,0000)\end{array}$ & $\begin{array}{c}0,493855 \\
(0,000000)\end{array}$ & $\begin{array}{c}5,212273 \\
(0,7347)\end{array}$ & $\begin{array}{c}0,017216 \\
(0,8956)\end{array}$ \\
\hline FINANS $^{*}$ & $\begin{array}{c}0,689557 \\
(0,0000)\end{array}$ & $\begin{array}{c}0,467297 \\
(0,000000)\end{array}$ & $\begin{array}{c}14,90797 \\
(0,0610)\end{array}$ & $\begin{array}{c}1,057060 \\
(0,3039)\end{array}$ \\
\hline$T^{\prime} B^{* * *}$ & $\begin{array}{l}0,05584 \\
(0,7224)\end{array}$ & $\begin{array}{c}-0,018909 \\
(0,722382)\end{array}$ & $\begin{array}{c}11,62210 \\
(0,1689)\end{array}$ & $\begin{array}{r}32,48159 \\
(0,0000)\end{array}$ \\
\hline ZIRAAT $^{* * *}$ & $\begin{array}{c}-0,709558 \\
(0,2869)\end{array}$ & $\begin{array}{c}0,003494 \\
(0,428964)\end{array}$ & $\begin{array}{c}32,13843 \\
(0,001)\end{array}$ & $\begin{array}{c}3,040839 \\
(0,0812)\end{array}$ \\
\hline GARANTI $^{*}$ & $\begin{array}{l}0,73309 \\
(0,0000)\end{array}$ & $\begin{array}{c}0,366638 \\
(0,000004)\end{array}$ & $\begin{array}{c}8,307560 \\
(0,4040)\end{array}$ & $\begin{array}{c}7,153670 \\
(0,075)\end{array}$ \\
\hline HALK $^{* * *}$ & $\begin{array}{c}0,290575 \\
(0,1798) \\
\end{array}$ & $\begin{array}{c}0,039625 \\
(0,179787)\end{array}$ & $\begin{array}{c}16,05803 \\
(0,0416)\end{array}$ & $\begin{array}{r}0,247583 \\
(0,6188)\end{array}$ \\
\hline ISBANK $^{*}$ & $\begin{array}{c}1,155409 \\
(0,0008)\end{array}$ & $\begin{array}{c}0,202998 \\
(0,000773)\end{array}$ & $\begin{array}{c}3,998160 \\
(0,8573)\end{array}$ & $\begin{array}{c}0,167085 \\
(0,6828)\end{array}$ \\
\hline VAKIF $^{* *}$ & $\begin{array}{c}0,393435 \\
(0,0257)\end{array}$ & $\begin{array}{l}0,085947 \\
(0,02672) \\
\end{array}$ & $\begin{array}{c}8,307178 \\
(0,4041) \\
\end{array}$ & $\begin{array}{c}0,116675 \\
(0,7327) \\
\end{array}$ \\
\hline YAPI $^{* * *}$ & $\begin{array}{l}0,05730 \\
(0,7434)\end{array}$ & $\begin{array}{c}-0,019764 \\
(0,743428)\end{array}$ & $\begin{array}{c}10,10251 \\
(0,2579)\end{array}$ & $\begin{array}{l}0,02648 \\
(0,8703)\end{array}$ \\
\hline GENEL $^{*}$ & $\begin{array}{c}0,734996 \\
(0,0022)\end{array}$ & $\begin{array}{c}0,189494 \\
(0,002228)\end{array}$ & $\begin{array}{c}8,566987 \\
(0,3801)\end{array}$ & $\begin{array}{c}0,677331 \\
(0,4105)\end{array}$ \\
\hline ÖZEL ${ }^{*}$ & $\begin{array}{c}0,770403 \\
(0,0000)\end{array}$ & $\begin{array}{c}0,313786 \\
(0,000002)\end{array}$ & $\begin{array}{c}6,540663 \\
(0,5869)\end{array}$ & $\begin{array}{c}2,481934 \\
(0,1152)\end{array}$ \\
\hline $\mathrm{KAMU}^{* * *}$ & $\begin{array}{c}0,061380 \\
(0,9019)\end{array}$ & $\begin{array}{c}-0,021873 \\
(0,901858)\end{array}$ & $\begin{array}{c}33,20234 \\
(0,0001)\end{array}$ & $\begin{array}{r}0,033197 \\
(0,8554)\end{array}$ \\
\hline \multicolumn{5}{|c|}{$\begin{array}{l}\text { \%1düzeyinde anlamlılık } \\
\% 5 \text { düzeyinde anlamlılık } \\
{ }^{* * *} \text { istatistiki olarak anlamsız } \\
\text { LM Otokorelasyon Testi }\end{array}$} \\
\hline
\end{tabular}

Türk Bankacılık sektöründe faaliyet gösteren ilk on bankanın (varlık büyüklüğüne göre) analiz sonuçlarına bakıldığında bu bankaların beşinin \%1 anlamlılık düzeyinde aktif değişim ile kaldıraç oranları arasında pozitif bir bağıntı olduğu görülmüştür. Bu bankalardan sadece bir tanesi \%5 anlamlılık düzeyinde pozitif bir bağıntı içerisindedir. Diğer bankalar için anlamlı sonuçlara ulaşılamamıştır. Bu durumda anlamlı bulunan bağıntıdan hareketle Akbank T.A.Ş., Denizbank A.Ş., Finansbank A.Ş., Türkiye Garanti Bankası A.Ş., Türkiye iş Bankası A.Ş. ve Türkiye Vakıflar Bankası T.A.O kaldıraç oranlarını döngüsel olduğunu söylemek mümkündür. Türkiye Vakıflar Bankası T.A.O dışındaki iki kamu bankasının istatistikî olarak sonuçları bir anlam taşımadığı için kamu bankalarının kaldıraç oranlarının döngüselliği konusunda net bir sonuca ulaşılamamıştır.

Seçilen örneklemdeki mevduat bankalarının geneline bakıldığında kaldıraç oranlarının pozitif ve güçlü bir döngüsellik sergilediği görülmektedir. Daha öncede bahsedildiği gibi bu bankalar Türk Bankacılık sektörünün varlık büyüklüğü olarak \%85 gibi büyük bir oranda temsil ettiği için, genel anlamda Türk bankacılık sektörünün kaldıraç oranlarının döngüsel olduğu söylenebilir. 
Analiz sonuçları için yapılan varsayım testlerinde anlamlı çıkan sonuçların herhangi bir otokorelasyon ve çoklu varyans özelliği taşımadığı görülmektedir. Bu nedenle En Küçük Kareler Yöntemiyle yapılan analiz oldukça güvenilir sonuçlar sunmaktadır.

\section{SONUÇ}

2008 Mali Kriz öncesi kaldıraç oran/larının finansal genişleme dönemlerinde giderek yükselmesi bilanço büyüklerine yapmış olduğu katkı bakımından önemsenmemekteydi. 2008 yılında oluşan mali kriz sonrasında yapılan araştırmalar kaldıraç oranlarındaki bu sarmal döngüselliğin finansal bir hızlandırıcı mekanizma olarak çalıştığı ve sonuçta bu kontrol edilemez hızlanmanın banka iflasları ile sonuçlandığını göstermektedir. Ululslararası düzenlemeler olarak da BASEL II standartlarının bu riski görme konusundaki eksikliği BASEL III ile giderilmeye çalışılmıştır. BASEL III ile kaldıraç oranı üzerine kontrol edici yeni standartlar getirilsede Petersen ve diğ (2013) yapmış olduğu çalışmada vurgulandığı gibi bu kontrol mekanizması tek tiplilikten kaynaklı bazı sıkıntıları da içerisinde barındırmakta ve döngüsellikten meydana gelebilecek risklerin ortaya çıkarılmasında eksiklikler barındırmaktadır.

Aralık 2002-Aralık 2014 dönemlerini kapsayan Türk Bankacılık sisteminde faaliyet gösteren mevduat bankalarının kaldıraç oranlarının döngüselliğini araştıran bu çalışmada özel sektör bankalarının büyük oranda döngüsel olduğu ancak kamu bankaları için anlamlı bir sonuç çıkmadığı tespit edilmiştir.

Bu bankaların genel itibariyle Türk bankacılık sisteminin büyük oranda temsil kabiliyeti olduğu için sistemin kaldıraç oranlarının döngüsel olduğu sonucu çıkartılabilir. Bu sonuç Çalışkan (2011) ve Binici ve Köksal (2012) Türkiye için yapmış olduğu çalışmaların sonuçlarıyla örtüşmektedir.

Türk Bankacılık sektörü her ne kadar bankacılık alanında kendi içsel krizlerinden ders alarak 2008 Mali Krizini en az hasarla atlatsa da, gelecekte bir gelişmekte olan piyasa olarak, finansal genişleme ve daralma dönemlerini daha sıklıkla yaşaması muhtemeldir. Özellikle Türkiye'de özel sektör bankalarının belirli kısmının yönetiminin holdinglere ait olması Giordana ve Schumacher (2013)'in Lüksemburg için yapmış olduğu çalışmada tespit ettiği gibi kaldıraç döngüselliğinin getirmiş olduğu riskler bakımından ekstra bir tehdit oluşturmaktadır.

Bu bakımdan, çalışmada Türkiye'de faaliyet gösteren bankalarda kaldıraç döngüselliğinin devam ettiğinin tespiti önemlidir.

Bu tespitten hareketle, Türkiye'de finansal genişleme dönemlerinde piyasa düzenleyici kurumlar her ne kadar standartların koymuş olduğu zorunlukluklar olsa da döngüsellik karşıtı mekanizmaları kullandığında, bankaların aktif ve kredi büyüklüklerini yavaşlatıcı önlemleri alabilirler ve bankalarının bilançolarının daha stabil oluşmasına olanak verebilirler. Böylece döngüsellikten kaynaklı aşırı bilanço şişkinliği de giderilmiş olacağından döngüselliğin Türkiye'nin mali yapısını zayıflatıcı etkisi minimize edilecektir. Bunun yanında mikro bağlamda bankalar da finansal genişleme ve daralma dönemlerinde 
kendi yönetimlerinde bu döngüselliği kullanarak bankalarının bu dönemlerde daha yumuşak bir geçiş yapmasını sağlayabilirler.

\section{KAYNAKÇA}

Adrian, T. ve Shin, H.S. (2008). Liquidity and Leverage. International Monetary Fund Financial Cycles, Liquidity, and Securization Conference.

Adrian, T. ve Shin, H.S. (2010). Liquidity and Leverage. Journal of Financial Intermadiation. 19(3), 418-437.

Athanasoglou, P. ve diğ. (2014), Bank Procyclicality and Output: Issues and Policies, Journal of Economics and Business, 72, 58-83.

BASEL Committee on Banking Supervision September Meeting, (2010), Press Release, 1-7.

Baglioni, A. ve diğ. (2013). Is The Leverage of European Banks Procyclical? Empir Econ. Springer. 45, 1251-1266.

Binici, M. ve Köksal, B. (2012). Is The Leverage of Turkish Banks Procyclical? Central Bank Review. 12(2), 11-24.

Brummitt, C.D. ve diğ. (2014), Inside Money, Procyclical Leverage, and Banking Catastrophes. Plos One, 9(8), 112.

Çalışkan, A. (2011). Türk Bankalarının Kaldıraç Davranışı: Küresel Krizden Nasıl Kurtuldular? iktisat, İ̧sletme ve Finans Dergisi. 26 (307), 75-104.

Damar, H.E. (2010). Leverage, Balance Sheet Size and Whosale Funding. Bank of Canada Working Paper. 39, 1-44.

Danielsson, J ve diğ. (2012). Procyclical Leverage and Endogenous Risk. Available at SSRN 1360866. http://ssrn.com/abstract=1360866, 1-43.

Giordana, G. ve Schumacher, I. (2013), What Are The Bank-Specific and Macroeconomic Drivers of Banks' Leverage? Evidence from Luxembourg. Empirical Economics, 45, 905-908.

Gropp, R. ve Heider, F. (2010). The Determinant sof Bank Capital Structure. Review of Finance. 14, 587-622.

Kalemli-Ozcan ve diğ. (2011). Leverage Across Firms, Banks and Countries. NBER Working Paper Series. No: $17354,1-55$.

M'Kinnon, J.G. (1996). Numerical Distiribution Functions for Unit Root and Cointegration Tests. Journal of Applied Economics. 11, 601-608.

Petersen, M.A. ve diğ.(2013). A Basel Perspective on Bank Leverage. Applied Financial Economics, 23 (17), 13611369.

Veri, (2015). Türkiye Bankalar Birliği internet sitesi. http://www.tbb.org.tr/tr/banka-ve-sektor-bilgileri/verisorgulama-sistemi/60. 